\title{
Variations in lignin monomer contents and stable hydrogen isotope ratios in methoxy groups during the biodegradation of garden biomass
}

\section{Qiangqiang LU}

Shaanxi Academy of Sciences, Xi'an Botanical Garden of Shaanxi Province (Institute of Botany of

Shaanxi Province)

Lili JIA

Northwest A\&F University

Mukesh Kumar AWASTHI

Northwest A\&F University

\section{Guanghua JING}

Shaanxi Academy of Sciences, Xi'an Botanical Garden of Shaanxi Province (Institute of Botany of

Shaanxi Province)

\section{Yabo WANG}

Shaanxi Normal University

\section{Liyan HE}

Shaanxi Academy of Sciences, Xi'an Botanical Garden of Shaanxi Province (Institute of Botany of Shaanxi Province)

\section{Ning ZHAO}

Shaanxi Academy of Sciences, Xi'an Botanical Garden of Shaanxi Province (Institute of Botany of Shaanxi Province)

\section{Zhikun CHEN}

Shaanxi Academy of Sciences, Xi'an Botanical Garden of Shaanxi Province (Institute of Botany of Shaanxi Province)

\section{Zhao ZHANG}

Shaanxi Academy of Sciences, Xi'an Botanical Garden of Shaanxi Province (Institute of Botany of Shaanxi Province)

\section{Xinwei SHI ( $\nabla$ sxw@ms.xab.ac.cn )}

Shaanxi Academy of Sciences, Xi'an Botanical Garden of Shaanxi Province (Institute of Botany of Shaanxi Province)

\section{Research Article}

Keywords: Biodegradation, Lignin, Monomer ratio, $\delta 2 \mathrm{HLM}$ values, Garden biomass 
Posted Date: March 3rd, 2022

DOI: https://doi.org/10.21203/rs.3.rs-1371341/v1

License: (c) (i) This work is licensed under a Creative Commons Attribution 4.0 International License. Read Full License 


\section{Abstract}

Lignin is the most difficult aromatic substance to degrade. Selective biodegradation under mild conditions is a promising method, but the dynamic variations in lignin monomers during the biodegradation of lignocellulose are not fully understood. In this study, we examined degradation of lignin monomers and changes in stable hydrogen isotope ratios $\left(\delta^{2} \mathrm{H}_{\mathrm{LM}}\right)$ in methoxy groups to test the potential of Pseudomonas mandelii, Aspergillus fumigatus, and their co-culture. The degradation weight loss and net degradation loss of lignocellulosic biomass during biodegradation improved dramatically with fungal inoculation. Syringyl monolignol (S-lignin), which contains two methoxy groups, was more difficult to degrade than guaiacyl (G-lignin), which contains only one methoxy group. The $\delta^{2} \mathrm{H}_{\mathrm{LM}}$ values generally remained stable during the depolymerization of lignin. The fluctuation of $\delta^{2} \mathrm{H}_{\mathrm{LM}}$ values during the initial phase of biodegradation may be related to the loss of pectic polysaccharides (another methoxy donor) from the leaves. Our statistical analysis showed that $\delta^{2} \mathrm{H}_{\mathrm{LM}}$ values did not differ among the microbial cultures or change over time despite decreasing $G / S$ ratios. Our results suggest that lignin monomer ratios can be used to monitor differences in microbial metabolism during lignocellulose biodegradation, whereas $\delta^{2} \mathrm{H}_{\mathrm{LM}}$ signatures cannot be used.

\section{Highlights}

- We tested biodegradation by 3 microbes to evaluate the changes in lignin monomers.

- Guaiacyl monolignol is more easily degraded than syringyl, especially by fungi.

- Lignin $\delta^{2} H_{L M}$ values were independent of the decrease in $G / S$ ratio or methoxy loss.

\section{Introduction}

With the rapid worldwide expansion of urbanization, garden biomass is becoming a major component of organic solid wastes ${ }^{1}$. However, its unrestrained disposal would waste a potentially important resource (i.e., organic matter) and potentially even become a source of environmental pollution ${ }^{2}$. Biodegradation, including composting, has garnered particular attention as a way to dispose of this waste while efficiently recovering chemicals and nutrients that have commercial or ecological value ${ }^{3,4}$. Indeed, composting under controlled or natural conditions can successfully decompose biomass and allow the production of potentially useful organic products through multiple microbial metabolic pathways ${ }^{5,6}$. Nevertheless, depolymerization of lignin is a particular challenge during the degradation of lignocellulose because it inhibits decomposition due to macromolecular polymerization reactions and the degradation-resistant properties of aromatic structures ${ }^{7,8}$.

Lignin, the second-most abundant biomacromolecule, is predominantly composed of three 4hydroxyphenylpropanoid units: guaiacyl monolignols (G-lignin), syringyl monolignols (S-lignin), and minor amounts of $p$-hydroxyphenyl monolignols (H-lignin). These compounds are highly interconnected 
through aryl ether, biphenyl ether, resinol, phenyl-coumaran and diphenyl bonds, which are resistant to breakage ${ }^{9}$. However, because the components of lignin have multiple cleavage sites for enzymatic hydrolysis and high oxidation potential for their aromatic skeletons, biodegradation is an efficient and cost-effective approach for lignin depolymerization ${ }^{10,11}$. The biological process of enzymatic hydrolysis of lignin begins with deconstruction to form heterogeneous aromatic hydrocarbons, which are then consumed by the central carbon metabolism ${ }^{12}$. In general, these ligninolytic enzymes (extracellular oxidases), which include laccase, manganese peroxidase, and lignin peroxidase, are mainly secreted by fungi and some bacteria ${ }^{13,14}$. Previous research focused more on screening to identify lignin-degrading microorganisms and the expression of multienzyme activities; however, studies on the efficiency of lignin degradation by different microorganisms have been neglected ${ }^{15}$.

Previous studies of the chemical transformations that occur during lignin depolymerization have indicated that monolignol S-lignin, with two methoxy $\left(\mathrm{OCH}_{3}\right)$ groups at the meta-positions (positions 3 and 5) of the phenylpropanoid structure, is more difficult to depolymerize than G-lignin (with a single $\mathrm{OCH}_{3}$ group) and $\mathrm{H}$-lignin (with no $\mathrm{OCH}_{3}$ groups) ${ }^{16-18}$. This is mainly due to the irreversible methylation of coniferyl and sinapyl alcohols (3/5-0-methylation) via caffeic acid 0-methyltransferases, caffeoyl-CoA 0methyltransferases, or both, which is different from the isomerization of aromatic hydrocarbons and the bonding of the propane side chains during monolignol biosynthesis ${ }^{9}$. Therefore, these stable $\mathrm{OCH}_{3}$ groups are not only chemical markers of structural differences in lignin monomers but also notable precursors of numerous organic compounds ${ }^{19}$. To date, lignin methoxy groups have been widely applied in biogeochemical, paleoclimatic, traceability and authenticity studies, among other fields ${ }^{20-23}$.

Because the hydrogen and carbon atoms in $\mathrm{OCH}_{3}$ are not exchanged with those from source water or metabolites, their stable isotope ratios serve as an indicator of their source ${ }^{24,25}$. For example, the robust relationship (apparent isotope fractionation) of the stable hydrogen isotope between plant source water (mainly local precipitation, $\delta^{2} \mathrm{H}_{\text {Pre }}$ ) and lignin methoxy groups $\left(\delta^{2} \mathrm{H}_{\mathrm{LM}}\right)$ can serve as a paleoclimate and hydrology proxy and can be used to trace the flow of water through biogeochemical cycles ${ }^{21,26-28}$. In addition, Anhäuser et al. ${ }^{29}$ reported that $\delta^{2} \mathrm{H}_{\mathrm{LM}}$ values remained constant during natural degradation of foliar litter and were independent of the total mass loss and methoxy content; thus, they could provide reliable information for palaeoclimatological and biogeological reconstructions. Although the loss of methoxy groups had no essential impact on the $\delta^{2} \mathrm{H}_{\mathrm{LM}}$ signature, we lack detailed information about the variability in $\delta^{2} \mathrm{H}_{\mathrm{LM}}$ during biotic and abiotic degradation, particularly in terms of the different roles and characteristics of bacterial versus fungal degradation. Moreover, previous research focused more on the adsorption capacities and conversion efficiencies of the enzymes for lignin ${ }^{30}$, and we found no studies of the dynamic variations in lignin monomers and their $\delta^{2} \mathrm{H}_{\mathrm{LM}}$ values during their degradation by different microorganisms.

To address these limitations of our knowledge, we designed the present study to compare the variations in lignin during biodegradation of garden biomass. We chose a fungal strain and a bacterial 
strain, and tested their biodegradation effectiveness both separately and in combination under controlled thermophilic conditions. We performed gas chromatograph-mass spectrometry (GC-MS) and gas chromatograph-isotope ratio mass spectrometry (GC-IRMS) analyses of the degradation residues at 2day intervals during a 15-day study. We hypothesized that the lignin monomers and their $\delta^{2} \mathrm{H}_{\mathrm{LM}}$ values would change independently and reveal different relative roles of bacteria versus fungi. Our specific objectives were to (1) reveal the variability in lignin degradation by Pseudomonas mandelii, Aspergillus fumigatus, and their co-culture, and (2) evaluate the dynamic changes in lignin degradation based on the ratio of the two monomers and on $\delta^{2} \mathrm{H}_{\mathrm{LM}}$ values of the degradation residues. Our ultimate goal was to determine the potential application of lignin monomers and their specific functional groups as a proxy for the progress of biomass biodegradation.

\section{Materials And Methods}

Materials and microorganisms. We used multisource garden biomass composed of leaf litter, dead wood, and horticultural pruning residues that were collected at the Xi'an Botanical Garden (Shaanxi, China). Each component was cut with pruning shears into fragments approximately $1 \mathrm{~cm}$ long and thoroughly mixed to create pooled samples with equal weight proportions of each material. The homogeneous mixtures were then added to conical glass flasks. The main chemical composition of the bulked materials is cellulose (32\%), hemicellulose (17\%), and total lignin (27\%), which contain lignin monomers in the following proportions: G-lignin (10.0\%), S-lignin (13.6\%), G\&S-lignin (23.6\%), and total methoxy groups (5.7\%).

The microbial inoculate used in this study were the bacterium Pseudomonas mandelii (strain QL-1, hereafter "PM"), the fungus Aspergillus fumigatus (strain QL-4, hereafter "AF"), and the combination of the two strains (combination of QL-1 and QL-4, hereafter "PM+AF"). These strains were isolated from soil humus in the understorey of a natural forest in the Qinling Mountains in September, 2019 and further identified by means of $16 \mathrm{~S}$ ribosomal DNA and internally transcribed spacer sequencing technology at Beijing Liuhe BGI Technology Co., Ltd. (Beijing, China) (Fig. S1). We used a chromatographic-grade internal standard (tetracosane, 99.5\%) and the reaction reagent (hydriodic acid, 55 to $58 \%$ ) purchased from Macklin (Shanghai, China). All the other chemicals were of analytical grade and purchased from Kemiou Chemical Reagent Co., Ltd. (Tianjin, China).

Biodegradation experiment. Before the biodegradation experiment, all biomass materials were thoroughly homogenized using a vortex oscillator $(5 \mathrm{~min})$, sterilized at high temperature $\left(121^{\circ} \mathrm{C}\right)$ and pressure $(103 \mathrm{KPa})$ for $20 \mathrm{~min}$, and then dried in an oven at $85^{\circ} \mathrm{C}$ for $8 \mathrm{~h}$. To capture the variation in lignin monomers and $\delta^{2} \mathrm{H}_{L M}$ values of the degradation residues, we performed biodegradation experiments both separately for each microbe (PM and $A F)$ and using their combination as a co-culture (PM+AF). For the separate microbial strains, we used liquid suspensions with similar cell concentrations $\left(10^{7}\right.$ to $10^{8}$ $\mathrm{CFU} / \mathrm{mL}$ ), which were cultured in Luria-Bertani medium for $\mathrm{PM}$ and potato dextrose agar medium for $\mathrm{AF}$, 
respectively. The co-culture suspension was produced by mixing the same volumes used in the singlestrain suspensions.

The experimental setup and operation followed the method of Yoon and $\mathrm{Ji}^{31}$, with slight modifications. In summary, we added $30 \mathrm{~mL}$ of $5 \mathrm{mmol} \cdot \mathrm{L}^{-1}$ phosphoric acid buffer $(\mathrm{pH} 7.0)$ to a $250-\mathrm{mL}$ conical flask containing $5 \mathrm{~g}$ of the homogenized garden biomass. Subsequently, we inoculated $0.5 \mathrm{~mL}$ (a $10 \%$ volume to mass ratio) of the cultured suspension into the flask and then sealed the opening with breathable film (Mlbio, Shanghai, China). We used the same volume $(0.5 \mathrm{~mL})$ of sterile water as a control treatment, which included $30 \mathrm{~mL}$ of the buffer solution. The biodegradation experiments were then performed in the dark using a shaking incubator at $45^{\circ} \mathrm{C}$ and $150 \mathrm{rpm}$ for 15 days. We created 84 batches (three replicates in a given measurement period for the three inoculations and the control) in seven sampling periods.

\section{Sample collection and analysis.}

Sample collection. We observed the degradation status daily, and added sterile water, as necessary, to maintain a consistent solution volume. We collected three replicate batches of degradation residues per experiment as analytical samples on days $3,5,7,9,11,13$, and 15 . The initial samples on day 0 were obtained before we began the degradation experiment. We washed the samples three times with $15 \mathrm{~mL}$ of sterile water, filtered them, and dried the solids $\left(85^{\circ} \mathrm{C}\right)$ to constant weight. The degradation weight loss $(D W L, \%)$ of garden biomass was calculated as follows:

$$
D W L=\left(M_{\mathrm{b}}-M_{\mathrm{e} \text { or } \mathrm{c}}\right) / M_{\mathrm{b}} \times 100 \%
$$

where $M_{\mathrm{b}}$ is the initial amount of materials $(5000 \mathrm{mg})$, and $M_{\mathrm{e}}$ and $M_{\mathrm{c}}$ represent the difference $(\mathrm{mg})$ between the initial (b) and residual material amounts of the experimental and control groups (e or $\mathrm{c}$, respectively) on day $n$ of biodegradation. Net degradation loss $(N D L, \%)$ of garden biomass was the difference in $D W L$ between the inoculation experiment and the uninoculated control. The analytical samples were ground (to a diameter $<0.1 \mathrm{~mm}$ ) prior to the lignin monomer content and lignin methoxy $\delta^{2} \mathrm{H}_{\mathrm{LM}}$ measurements.

Lignin monomers composition analysis. Qualitative and quantitative analyses of lignin monomers were accomplished by the thioacidolysis reaction, which can effectively cleave the ether linkages of lignin monolignols and yield thioester derivatives ${ }^{32}$. The composition of lignin monomers in the degradation residues were measured by using a 7890B gas chromatograph equipped with G4513A auto-injector, coupled to a 7000D mass spectrometer (GC-MS; Agilent, USA). The GC was fitted with a HP-5MS column (30 m $\times 0.32 \mathrm{~mm} \times 0.25 \mu \mathrm{m}$; Agilent, USA) and the following conditions were employed: inlet temperature $250{ }^{\circ} \mathrm{C}$, injection volume $1 \mu \mathrm{L}$, split injection (10:1), initial oven temperature at $150{ }^{\circ} \mathrm{C}$ for $2 \mathrm{~min}$, ramp at $20^{\circ} \mathrm{C} / \mathrm{min}$ to $250^{\circ} \mathrm{C}$ and hold for $5 \mathrm{~min}$. Helium was used as the carrier gas at constant flow of $1.0 \mathrm{~mL} / \mathrm{min}$. The following MS conditions were used: electron ionization (EI) mode, ion source temperature $230^{\circ} \mathrm{C}$, interface temperature $250^{\circ} \mathrm{C}$, electron energy $70 \mathrm{eV}$, solvent delay $3.5 \mathrm{~min}$, scan 
range from 40 to $650 \mathrm{amu}$. The GC-MS was run in selective ion monitoring mode for the following molecular ions and retention times: m/z 269 for G-lignin derivant at $17.5 \mathrm{~min}, \mathrm{~m} / \mathrm{z} 299$ for the S-lignin derivant at $20.8 \mathrm{~min}$, and $\mathrm{m} / \mathrm{z} 338$ for internal standard tetracosane at $12.7 \mathrm{~min}$.

The final determination of lignin monomer contents followed the method of Lapierre ${ }^{33}$, where the response factor $(k)$ equalled the ratio of the relative concentration to the relative area between the internal standard and the target sample:

$$
k=\left(C_{s} / C_{\mathrm{i}}\right) /\left(A_{\mathrm{s}} / A_{\mathrm{i}}\right)
$$

where $k$ was equal to $1.5, C_{\mathrm{s}}$ and $C_{\mathrm{i}}$ represent the concentrations of the lignin monomer derivatives and the tetracosane, respectively, and $A_{\mathrm{s}}$ and $A_{\mathrm{i}}$ represent the corresponding peak areas, respectively. Moreover, we assumed that the thioacidolysis reaction was sufficient and complete in this study, and defined the conversion of substrate and the recovery of internal standard to be $100 \% 34,35$. We then converted the sample lignin monomer contents into the amounts of G- and S-lignin using the ratio of the molecular weight between the monolignols and their derivatives $(0.67 \mathrm{for}$ G-lignin and 0.70 for Slignin) ${ }^{32}$. Net degradation loss (NDL, \%) of G-lignin and S-lignin was the difference in lignin monomer contents between the inoculation experiments and the uninoculated control, and the net degradation loss rate $\left(N D R, \% \cdot\right.$ day $\left.^{-1}\right)$ was defined as the net degradation loss of lignin monomers at every degradation stage. For more details of the thioacidolysis reaction, GC-MS conditions, and chromatographic chart, please refer to the Supplementary information (Figs. S2, S3a; Supplemental Text S1.1).

Measurement of the stable hydrogen isotope ratio of lignin methoxy groups. $\delta^{2} \mathrm{H}_{L M}$ values of analytical powdered samples were measured as headspace iodomethane $\left(\mathrm{CH}_{3} \mathrm{I}\right)$, released upon the selective substitution reaction between the methoxy groups of the degradation residues and hydriodic acid $(\mathrm{HI})$. We followed the established method of Keppler et al. ${ }^{25}$ and Greule et al. ${ }^{36}$ with minor modifications $^{28}$. Specifically, $0.5 \mathrm{~mL}$ of $\mathrm{HI}$ was added to the degradation residues $(10 \pm 0.5 \mathrm{mg})$ in a brown crimp glass vial ( $1.5 \mathrm{~mL}$; Agilent, USA) containing a tiny magnet. The vial was sealed with aluminum caps containing PTFE-lined butyl rubber septa ( $11 \mathrm{~mm}$ crimp and thickness $0.9 \mathrm{~mm}$ ) and stirred in an oil bath at $120^{\circ} \mathrm{C}$ for $30 \mathrm{~min}$. This conversion temperature was a weighted value based on validation by Keppler et al. ${ }^{25}$ at $110^{\circ} \mathrm{C}$ and Greule et al. ${ }^{36}$ at $130{ }^{\circ} \mathrm{C}$. After incubating, the sub-samples were allowed to equilibrate at $22 \pm 0.5^{\circ} \mathrm{C}$ (in an air-conditioned room) for at least $40 \mathrm{~min}$. Finally, an aliquot ( 80 to $100 \mu \mathrm{L}$ ) of the $\mathrm{CH}_{3}$ l was directly injected into the analytical system by using a manual gastight syringe (100 $\mu \mathrm{L}$; Hamilton, USA).

$\delta^{2} \mathrm{H}_{\mathrm{LM}}$ values of $\mathrm{CH}_{3} \mathrm{l}$ were measured using a TRACE 1310 gas chromatograph (GC), coupled with an ISOLINK II Delta V Advantage isotope-ratio mass spectrometer (IRMS) via a thermal conversion reactor (ceramic tube $\left[\mathrm{Al}_{2} \mathrm{O}_{3}\right.$ ], length $320 \mathrm{~mm}, 0.5 \mathrm{~mm}$ i.d., reactor temperature $1400{ }^{\circ} \mathrm{C}$ ) (Thermo Fisher, Germany). The measurements were performed at the laboratory of biogeochemistry, Shaanxi Normal 
University. The GC was fitted with a TG-5MS column ( $30 \mathrm{~m} \times 0.25 \mathrm{~mm} \times 0.25 \mu \mathrm{m}$; Thermo Fisher, Germany), and based on the following parameters: inlet temperature $200^{\circ} \mathrm{C}$, split injection (12:1), initial oven temperature at $40^{\circ} \mathrm{C}$ for $3.8 \mathrm{~min}$, ramp at $20^{\circ} \mathrm{C} / \mathrm{min}$ to $80^{\circ} \mathrm{C}$ and holding for $1 \mathrm{~min}$, and then ramp at $40^{\circ} \mathrm{C} / \mathrm{min}$ to a final temperature of $100^{\circ} \mathrm{C}$ and hold for $3 \mathrm{~min}$. Helium was used as the carrier gas at a constant flow of $0.8 \mathrm{~mL} / \mathrm{min}$. High purity hydrogen gas (99.999\%; Beijing AP Baif Gases Industry Co., China) was used as the monitoring gas. The $\mathrm{H}_{3}{ }^{+}$factor ranged from 4.7 to $5.0 \mathrm{ppm} / \mathrm{nA}$ during the measurement period.

To improve accuracy, the measurement should follow the principle of identical treatment for the analytical samples and reference materials, and the $\delta^{2} \mathrm{H}_{\mathrm{LM}}$ values should be normalised by a two-point calibration37. However, due to the lack of available commercial samples with true $\delta^{2} \mathrm{H}_{\mathrm{LM}}$ values as reference materials, we could only use two homogenized wood samples from different geographical locations and tree species to examine the stability and parallelism of the GC-IRMS results. These two wood samples have been recently measured by Frank Keppler's lab at Heidelberg University against their standards ${ }^{38}$. Hence, the reported $\delta^{2} \mathrm{H}_{L M}$ data in this study were expressed relative to the monitoring hydrogen gas and calibrated against our in-house standards. Furthermore, milli-Ureys $(\mathrm{mUr})$ were used as the unit of isotope $\delta$-values instead of the V-SMOW (Vienna Standard Mean Ocean Water) scale in per mil (\%o ${ }^{39}$. The standard deviations $(n=3$ or $7,1 \sigma)$ were in the range of 0.6 to $2.4 \mathrm{mUr}$. For more details about the substitution reaction, measurement conditions, correction method, and chromatographic charts, please refer to the Supplementary information (Fig. S2, S3b and Supplemental Text S1.2).

Statistical analysis. The reported data are the mean \pm standard deviation of the three replicated experiments. The statistical significance of the measurements was evaluated by one-way analysis of variance (ANOVA, with significance at $P<0.05$ ), and when the ANOVA results were significant, we used Tukey's HSD test to identify pairs of values that differed significantly between the degradation experiments.

\section{Results And Discussion}

Differences in the microbial degradation of lignocellulosic biomass. Figure 1 and Table $\mathrm{S} 1$ showed the degradation weight loss ( $D W L, \%)$ and net degradation loss (NDL, \%) of garden biomass at 2-day intervals during the study period. At a given degradation stage, both microbes were able to degrade the lignocellulosic biomass, but co-culture of the microorganisms frequently achieved a significantly $(P<$ $0.05)$ greater degradation. In the 15-day degradation experiments, the $D W L$ value of the bacterium (PM experiment) increased from $4.3 \%$ (day 3 ) to $18.9 \%$ (day 15 ), and the corresponding $N D L$ value increased from $3.1 \%$ to $11.9 \%$ with a linear fit and a slope of $1.16(P<0.001)$. The final $D W L$ value for the fungus (AF experiment) increased to $23.9 \%$, and the $N D L$ value increased from $3.9 \%$ to $17.0 \%$ with a slope of 1.68 $(P<0.001)$. As expected, the biodegradation efficiency in the co-culture (PM+AF experiment) was generally higher than that of the single strains, with a final $D W L$ value as high as $26.7 \%$ and a fitted slope 
of $1.75(P<0.001)$ for NDL. Usually, a multi-species symbiotic mixture is the best approach to promote diverse enzyme production and synergistic effects ${ }^{40}$. This is mainly because co-cultivation of different species can trigger more responses to chemical signals than would be possible with cultivation of a single fungus or bacterium ${ }^{41}$.

The conversion efficiency of degraded substances showed a large increase starting on day 7, especially in the fungal inoculation experiments (AF and PM+AF). Small molecules such as amino acids are metabolized first by microorganisms, followed by precursors (i.e., cellobiose, xylose, and oligomers) of refractory macromolecular substances ${ }^{3,42}$. Except for some materials with good thermo-solubility, these degraded substances are mainly derived from polysaccharide units. Thus, efficient hydrolysis of cellulose and hemicellulose was evident at the early stages of the three inoculation experiments. As reported by many studies, the lignocellulase-production capacity and enzyme activity levels of fungi were much higher than those of bacteria ${ }^{43,44}$. Although both $P$. mandelii and $A$. fumigatus in this study belong to the group of leaf-litter-decomposing microorganisms, the highest degradation efficiency was obtained in the co-cultivation. In addition, fungi have a high capacity to depolymerize lignocellulose, and produce various extracellular enzymes that catalyze this decomposition process ${ }^{3,45}$. In contrast, bacteria that are more environmentally adapted mainly secrete some $\beta$-1,4-glucosidase, endoglucanases, cellobiohydrolases, and xylanases, and some coenzymes for the hydrolysis of polysaccharides ${ }^{46,47}$. Therefore, the combined fungal-bacterial consortium has a unique biodegradation advantage due to synergies among the species and enzymes.

Degradation dynamics of the lignin monomers. The changes in the content of lignin monomers (G-and S-lignin) showed similar patterns in the PM, AF, and PM+AF experiments (Fig. 2 and 3). Within the first 5 days, the G-lignin and S-lignin contents decreased slightly, from $10.0 \%$ and $13.6 \%$ to $9.6 \%$ and $13.0 \%$, respectively, for $\mathrm{PM}$, to $9.5 \%$ and $13.1 \%$ for $\mathrm{AF}$, and to $8.9 \%$ and $12.8 \%$ for $\mathrm{PM}+\mathrm{AF}$ (Table S2). Afterwards, the decrease in G-lignin was particularly significant compared to S-lignin (Fig. 2a, b). At the end of the degradation period (day 15), the G-lignin content in the AF and PM+AF fungal experiments had decreased by 5.1 and 6.7 percentage points, respectively, whereas S-lignin decreased by only 3.4 and 3.8 percentage points, respectively (Table 1). The sum of the G- and S-lignin contents decreased by $4.5,8.5$, and 10.5 percentage points in the three inoculations, respectively (Fig. 2c, Table 1). The NDL values of G-lignin were much larger than those of S-lignin after day 7 (Table S3). Although the corresponding linear fit strengths for both lignin monomers were significant over the entire degradation period, the steepness and significance of the equations for the three experiments differed, with the slope greatest for PM+AF, followed by AF and PM (Fig. 3a). Furthermore, the net degradation loss rate (NDR) of G-lignin content had different but significant increase patterns throughout the degradation experiments, whereas for S-lignin the NDR continuously increased only in the AF experiment (Fig. 3b, S4). Overall, degradation loss of Glignin was much larger than that of S-lignin, and the highest degradation efficiencies were observed in the co-culture system. 
Previous research demonstrated that during lignocellulose biodegradation, lignin is mainly depolymerized by extracellular oxidases through a series of nonspecific oxidative pathways ${ }^{48}$. These unique lignin peroxidases, manganese peroxidases, and laccase are usually secreted by typical lignin-degrading fungi, which have stronger enzymatic hydrolysis selectivity and catalytic efficiency than the enzymes secreted by bacteria ${ }^{40,49}$. As Figures 2 and 3 showed, the degradation of both G-lignin and S-lignin in the co-culture experiment increased greatly compared to the single microbial strains, which may have resulted from the action of multiple catalysts and stronger oxidation capacity of the enzymes ${ }^{13,50,51}$. Structurally, the different biodegradation of lignin is probably caused by structural differences in the individual monomer units (Fig. 4a, b), with ferulic acid and syringic acid acting as precursors for G- and Slignin degradation (Fig. 4c), which are carbon and material sources for microbial cell growth and metabolic pathways ${ }^{14,15}$. In general, ferulic acid can be transformed into the intermediate vanillic acid via three different oxidation pathways and a side-chain reduction pathway, whereas syringic acid can eventually be assimilated into 4-oxalomesaconate and further requires 0-demethylase for demethylation ${ }^{52,53}$. In addition, in combination with the irreversibility of methylation in lignin biosynthesis ${ }^{9}$, we observed that S-lignin (which has two methoxy groups) is more difficult to degrade than G-lignin (which has only one methoxy group), possibly due to the chemical stability of the methoxy groups or even to a certain biological inhibition of microbial growth ${ }^{54}$.

Variation of the lignin monomer ratios and $\delta^{2} \mathrm{H}_{L M}$ values. We further characterized the changing characteristics of lignin degradation using the lignin monomer ratios $(G / S)$ and the methoxy $\delta^{2} H_{L M}$ values. The $G / S$ ratios of the degradation residues in the three inoculation experiments showed different rates of decrease starting from the initial ratio value of 0.74 (Fig. 5a, Tables 1 and S4). The largest decrease in the $G / S$ ratio occurred in the PM+AF experiment, with a final value of 0.33 , followed by the AF experiment (0.47) and the PM experiment (0.58). In contrast, the $G / S$ ratio in the uninoculated control experiment remained essentially constant $(0.73 \pm 0.01)$ throughout the degradation period (Fig. $5 a)$. Furthermore, based on the theoretical relative molecular mass ratio of methoxy groups to lignin monomers (17.2\% for G-lignin and $29.5 \%$ for S-lignin), we calculated that the methoxy group content of the degradation residues decreased from the initial $5.7 \%$ to a final value of $3.2 \%$ (PM+AF), versus $3.9 \%$ (AF) and $4.8 \%$ (PM) (Table 1). These findings further confirm our observations that G-lignin is more susceptible to degradation than S-lignin and that both forms of degradation occur faster in experiments with fungal involvement.

The initial mean $\delta^{2} \mathrm{H}_{\mathrm{LM}}$ value of the bulk material before the degradation experiments was $-230.4 \pm 1.5$ $\mathrm{mUr}$, which is close to the value $(-233.6 \pm 9.4 \mathrm{mUr}, n=119)$ in our research group's multi-year measurements of tree-ring wood (manuscript under review). Because these tree wood samples were collected from the Qinling Mountains, just $30 \mathrm{~km}$ away from where we collected garden biomass samples in the present study, the consistency of the two sets of $\delta^{2} \mathrm{H}_{\mathrm{LM}}$ values suggests consistency of the plant source water (i.e., local precipitation). In addition, except for the fluctuation of the $\delta^{2} \mathrm{H}_{\mathrm{LM}}$ values in the different culture experiments that occurred at the beginning of the degradation period, the measured 
$\delta^{2} \mathrm{H}_{\mathrm{LM}}$ values did not change significantly (ANOVA, $P<0.05$ ) during the degradation period (Table S5). The mean standard deviation $(n=3)$ for our analytical samples was greater than or equal to $1.5 \mathrm{mUr}$, which was clearly greater than what would be expected for ideal isotopic measurements ${ }^{36,38}$. This result can likely be explained by the reproducibility of the analytical technique, but the purity and complexity of the measured samples should also be taken into account. The experimental material used in the degradation experiments was a mixture of multiple sources of garden biomass, and the donors of the methoxy groups were mainly G- and S-lignin monomers, but also included plant-derived pectin and other aromatic intermediates. Pectin is the main polysaccharide in the cell wall of plant leaves, and is more likely than lignocellulose to be hydrolysed first ${ }^{55}$. Thus, the loss of pectin from the leaf litter might be responsible for the shift of the $\delta^{2} \mathrm{H}_{L M}$ values during the early stage of degradation ${ }^{29}$.

The final (day 15) $\delta 2 \mathrm{HLM}$ values in the four experiments ranged from $-227.5 \mathrm{mUr}$ to $-230.4 \mathrm{mUr}$, which were not significantly (ANOVA, $P<0.05$ ) different from the initial value (Fig. 5b, Tables 1 and S5).

Nevertheless, the shift (the average difference during the 15-day degradation period) of approximately 3.0 $\mathrm{mUr}$ between the fungal and bacterial experiments may not be negligible, when the enzymatic effects of isotopic fractionation and microbial biomass differences are taken into account ${ }^{56,57}$. From this result, it appears that the $\delta^{2} \mathrm{H}_{L M}$ values of the lignin methoxy groups did not depend on a decrease of the $\mathrm{G} / \mathrm{S}$ ratio or the loss of methoxy groups. In future research, if the $\delta^{2} \mathrm{H}_{L M}$ values of $\mathrm{G}$ - and S-lignin can be detected separately, and if differences in enzyme activities are considered, this will provide additional insights into the degradation mechanisms.

Table 1. Variations of the lignin monomers content, methoxy group content, monomer ratio, and $\delta^{2} \mathrm{H}_{L M}$ values in the bulk material and/or degradation residues from the beginning of biodegradation to the end.

\begin{tabular}{|c|c|c|c|c|c|c|c|}
\hline $\begin{array}{l}\text { Period } \\
\text { (Day) }\end{array}$ & Experiment & $\begin{array}{l}G M C \\
(\%)\end{array}$ & $S M C(\%)$ & $\begin{array}{l}\text { G\&SMC } \\
(\%)\end{array}$ & $M G C(\%)$ & $G / S$ ratio & $\begin{array}{l}\delta^{2} \mathrm{H}_{\mathrm{LM}} \\
(\mathrm{mUr})\end{array}$ \\
\hline $\begin{array}{l}\text { Initial (day } \\
\text { 0) }\end{array}$ & Control & $\begin{array}{l}10.0 \pm \\
0.2\end{array}$ & $\begin{array}{l}13.6 \pm \\
0.3\end{array}$ & $\begin{array}{l}23.6 \pm \\
0.4\end{array}$ & $\begin{array}{l}5.7 \pm \\
0.12\end{array}$ & $\begin{array}{l}0.74 \pm \\
0.01\end{array}$ & $\begin{array}{l}-230.3 \pm \\
1.5\end{array}$ \\
\hline \multirow[t]{4}{*}{$\begin{array}{l}\text { Final (day } \\
15)\end{array}$} & Control & $\begin{array}{l}9.2 \pm \\
0.2 \mathrm{a}\end{array}$ & $\begin{array}{l}13.2 \pm \\
0.3 \mathrm{a}\end{array}$ & $\begin{array}{l}22.4 \pm \\
0.4 \mathrm{a}\end{array}$ & $\begin{array}{l}5.5 \pm \\
0.14 a\end{array}$ & $\begin{array}{l}0.70 \pm \\
0.02 \mathrm{a}\end{array}$ & $\begin{array}{l}-230.4 \pm \\
1.9 \mathrm{a}\end{array}$ \\
\hline & PM & $\begin{array}{l}7.0 \pm \\
0.2 \mathrm{~b}\end{array}$ & $\begin{array}{l}12.1 \pm \\
0.3 \mathrm{~b}\end{array}$ & $\begin{array}{l}19.1 \pm \\
0.3 \mathrm{~b}\end{array}$ & $\begin{array}{l}4.8 \pm \\
0.12 b\end{array}$ & $\begin{array}{l}0.58 \pm \\
0.00 \mathrm{~b}\end{array}$ & $\begin{array}{l}-230.0 \pm \\
2.3 \mathrm{a}\end{array}$ \\
\hline & $\mathrm{AF}$ & $\begin{array}{l}4.9 \pm \\
0.2 \mathrm{c}\end{array}$ & $\begin{array}{l}10.2 \pm \\
0.4 \mathrm{c}\end{array}$ & $\begin{array}{l}15.1 \pm \\
0.4 \mathrm{c}\end{array}$ & $\begin{array}{l}3.9 \pm \\
0.11 \mathrm{c}\end{array}$ & $\begin{array}{l}0.47 \pm \\
0.01 \mathrm{c}\end{array}$ & $\begin{array}{l}-227.5 \pm \\
2.2 \mathrm{a}\end{array}$ \\
\hline & $\mathrm{PM}+\mathrm{AF}$ & $\begin{array}{l}3.3 \pm \\
0.2 \mathrm{~d}\end{array}$ & $\begin{array}{l}9.8 \pm 0.3 \\
c\end{array}$ & $\begin{array}{l}13.1 \pm \\
0.4 \mathrm{~d}\end{array}$ & $\begin{array}{l}3.2 \pm \\
0.06 \mathrm{~d}\end{array}$ & $\begin{array}{l}0.33 \pm \\
0.02 \mathrm{~d}\end{array}$ & $\begin{array}{l}-228.1 \pm \\
1.1 \mathrm{a}\end{array}$ \\
\hline
\end{tabular}

Experiments: Control, uninoculated control; PM, Pseudomonas mandelii; AF, Aspergillus fumigatus; $\mathrm{PM}+\mathrm{AF}(\mathrm{P}+\mathrm{A})$, co-culture of the two microbes. $G M C$, guaiacyl (G-lignin) monomer content; $S M C$, syringyl 
(S-lignin) monomer content; G\&SMC, G\&S-lignin monomer content; MGC, methoxy group content. Different letters represent a significant difference $(P<0.05)$ at different experiments.

\section{Conclusion}

The results confirm our hypothesis that the lignin monomers and their $\delta^{2} \mathrm{H}_{L M}$ values would change independently and reveal different relative roles of bacteria versus fungi in biodegradation. The lignindepolymerizing ability of Aspergillus fumigatus, alone or in co-culture, was stronger than that of Pseudomonas mandelii alone. G-lignin was more easily degraded than S-lignin in all experiments. The measured $\delta^{2} H_{L M}$ values of the lignin methoxy groups in degradation residues showed no significant dependence on the lignin monomer content, $G / S$ ratio, or loss of methoxy groups. Our results provide a new perspective to investigate changes in the metabolism of different microorganisms during lignin biodegradation. Although the lignin monomer contents appear to be promising indicators of the progress of biodegradation, the $\delta^{2} \mathrm{H}$ values will require more study (e.g., specific methoxy differences between two monomers) to determine whether they can provide additional insights into biodegradation.

\section{Abbreviations}

$\mathrm{Al}_{2} \mathrm{O}_{3}$, aluminium oxide;

$\mathrm{AF}$, Aspergillus fumigatus strain;

CFU, colony-forming unit;

$\mathrm{CH}_{3} \mathrm{l}$, iodomethane;

Control, uninoculated control experiment;

$\delta^{2} H_{L M}$, stable hydrogen isotope ratio in lignin methoxy groups;

$\delta^{2} \mathrm{H}_{\text {Pre, }}$ stable hydrogen isotope ratio in precipitation;

$D W L$, degradation weight loss;

G-lignin, guaiacyl monolignol;

GC, gas chromatograph;

$\mathrm{HI}$, hydriodic acid;

H-lignin, $p$-hydroxyphenyl monolignol;

IRMS, isotope-ratio mass spectrometer; 
MS, mass spectrometer;

$N D L$, net degradation loss;

$N D R$, net degradation loss rate;

$\mathrm{OCH}_{3}$, methoxy group;

PM, Pseudomonas mandelii strain;

$\mathrm{PM}+\mathrm{AF}$, the co-culture of Pseudomonas mandelii and Aspergillus fumigatus,

PTFE, polytetrafluoroethylene;

S-lignin, syringyl monolignol.

\section{Declarations}

\section{Data availability}

The datasets used and/or analysed during the current study available from the corresponding author on reasonable request.

\section{Acknowledgements}

We thank Professor Xiaohong Liu (Shaanxi Normal University) for technical support with the $\delta^{2} \mathrm{H}_{\mathrm{LM}}$ measurements. We are also very grateful for Professor Frank Keppler and his research staff from Heidelberg University for constructive advice and help regarding measurement of the stable isotope ratios in lignin methoxy groups. This research was supported by the Natural Science Basic Research Program of Shaanxi (grants 2021JQ-968, 2020JM-708, 2020JQ-971) and the Local Science and Technology Program of Shaanxi Province (grants 2021ZDYF-GY-0020, 20193058YF046NS046).

\section{Author Contributions}

All authors contributed to the study conception and design. Methodology, investigation, visualization, and visualization were performed by Qiangqiang Lu, Guanghua Jing, Yabo Wang, Liyan He, Ning Zhao, and Zhao Zhang. The first draft of the manuscript was written by Qiangqiang Lu and reviewed and edited by Lili Jia and Mukesh Kumar Awasthi. Project administration and funding acquisition were carried out by Xinwei Shi and Zhikun Chen. All authors reviewed and approved the final manuscript. 


\section{Competing Interests}

The authors declare that there are no competing financial or non-financial interests.

\section{Additional information}

Supplementary data for this article can be found in the online e-version.

\section{References}

1. Liczbiński, P., \& Borowski, S. Effect of hyperthermophilic pretreatment on methane and hydrogen production from garden waste under mesophilic and thermophilic conditions. Bioresource Technol. 335, 125264. https://doi.org/10.1016/j.biortech.2021.125264 (2021).

2. Kundariya, N., Mohanty, S. S., Varjani, S., Ngo, H. H., Wong, J. W. C., Taherzadeh, M. J., Chang, J. S., $\mathrm{Ng}, \mathrm{H}$. Y., Kim, S. H. \& Bui, X. T. A review on integrated approaches for municipal solid waste for environmental and economical relevance: monitoring tools, technologies, and strategic innovations. Bioresource Technol. 342, 125982. https://doi.org/10.1016/j.biortech.2021.125982 (2021).

3. Onwosi, C. O., Igbokwe, V. C., Odimba, J. N., Eke, I. E., Nwankwoala, M. O., Iroh, I. N. \& Ezeogu, L. I. Composting technology in waste stabilization: on the methods, challenges and future prospects. J. Environ. Manage. 190, 140-157. https://doi.org/10.1016/j.jenvman.2016.12.051 (2017).

4. Wainaina, W., Awasthi, M. K., Sarsaiya, M. K., Chen, H., Singh, E., Kumar, A., Ravindran, B., Awasthi, S. K., Liu, T., Duan, Y. M., Kumar, S., Zhang, Z. Q. \& Taherzadeh, M. J. Resource recovery and circular economy from organic solid waste using aerobic and anaerobic digestion technologies. Bioresource Technol. 301, 122778. https://doi.org/10.1016/j.biortech.2020.122778 (2020).

5. Awasthi, M. K., Sarsaiya, S., Wainaina, S., Rajendrdan, K., Wang, Q., Kumar, S., Duan, Y., Awasthi, S. K., Pandey, A., Chen, H. \& Taherzadeh, M. A critical review of organic manure biorefinery models toward sustainable circular bioeconomy: technological challenges, advancements, innovations, and future perspectives. Renew. Sust. Energ. Rev. 111, 115-131. https://doi.org/10.1016/j.rser.2019.05.017 (2019).

6. Cheng, H. H. \& Whang, L. M. Resource recovery from lignocellulosic wastes via biological technologies: advancements and prospects. Bioresource Technol. 343, 126097. https://doi.org/10.1016/j.biortech.2021.126097 (2022).

7. Lambertz, C., Ece, S., Fischer, R. \& Commandeur, U. Progress and obstacles in the production and application of recombinant lignin-degrading peroxidases. Bioengineered 7, 145-154. https://doi.org/10.1080/21655979.2016.1191705 (2016).

8. Cajnko, M. M., Oblak, J., Grilc, M. \& Likozar, B. Enzymatic bioconversion process of lignin: mechanisms, reactions and kinetics. Bioresource Technol. 340, 125655. https://doi.org/10.1016/j.biortech.2021.125655 (2021). 
9. Vanholme, R., Meester, B. D., Ralph, J. \& Boerjan, W. Lignin biosynthesis and its integration into metabolism. Curr. Opin. Biotech. 59, 230-239. https://doi.org/10.1016/j.copbio.2019.02.018 (2019).

10. Asina, F., Brzonova, I., Voeller, K., Kozliak, E., Kubatova, A., Yao, B. \& Ji, Y. Biodegradation of lignin by fungi, bacteria and laccases. Bioresource Technol. 220, 414-424. https://doi.org/10.1016/j.biortech.2016.124124 (2016).

11. Patil, V., Adhikari, S., Cross, P. \& Jahromi, H. Progress in the solvent depolymerization of lignin. Renew. Sust. Energ. Rev. 133, 110359. https://doi.org/10.1016/j.rser.2020.110359 (2020).

12. Chio, C., Sain, M. \& Qin, W. Lignin utilization: a review of lignin depolymerization from various aspects. Renew. Sust. Energ. Rev. 107, 232-249. https://doi.org/10.1016/j.rser.2019.03.008 (2019).

13. de Gonzalo, G., Colpa, D. I., Habib, M. H. M. \& Fraaije, M. W. Bacterial enzymes involved in lignin degradation. J. Biotechnol. 236, 110-119. https://doi.org/10.1016/j.jbiotec.2016.08.011 (2016).

14. Kamimura, N., Sakamoto, S., Mitsuda, N., Masai, E. \& Kajita, S. Advances in microbial lignin degradation and its applications. Curr. Opin. Biotech. 56, 179-186. https://doi.org/10.1016/j.copbio.2018.11.011 (2019).

15. Weng, C. H., Peng, X. W. \& Han, Y. J. Depolymerization and conversion of lignin to value-added bioproducts by microbial and enzymatic catalysis. Biotechnol. Biofuels 14, 84 . https://doi.org/10.1186/s13068-021-01934-w (2021).

16. Falade, A. O., Nwodo, U. U., Iweriebor, B. C., Green, E., Mabinya, L. V. \& Okoh, A. I. Lignin peroxidase functionalities and prospective applications. Microbiology 6, e00394. https://doi.org/10.1002/mbo3.394 (2017).

17. Jia, L. L., Qin, Y. J., Wang, J. \& Zhang, J. H. Lignin extracted by Y-valerolactone/water from corn stover improves cellulose enzymatic hydrolysis. Bioresource Technol. 302, 122901. https://doi.org/10.1016/j.biortech.2020.122901 (2020).

18. Morya, R., Kumar, M. \& Thakur, I. S. Bioconversion of syringyl lignin into malic acid by Burkholderia sp. ISTR5. Bioresource Technol. 330, 124981. https://doi.org/10.1016/j.biortech.2021.124981 (2021).

19. McRoberts, W. C., Keppler, F., Harper, D. B. \& Hamilton, J. T. G. Seasonal changes in chlorine and methoxyl content of leaves of deciduous trees and their impact on release of chloromethane and methanol at elevated temperatures. Environ. Chem. 12, 426-437. https://doi.org/10.1071/EN14208 (2015).

20. Keppler, F. \& Hamilton, J. T. G. Tracing the geographical origin of early potato tubers using stable hydrogen isotope ratios of methoxyl groups. Isot. Environ. Healt. S. 44, 337-347. https://doi.org/10.1080/10256010802507383 (2008).

21. Greule, M., Rossmann, A., Schmidt, H. L., Mosandl, A. \& Keppler, F. A stable isotope approach to assessing water loss in fruits and vegetables during storage. J. Agr. Food Chem. 63, 1974-1981. https://doi.org/10.1021/jf505192p (2015).

22. Geißler, K., Greule, M., Schäfer, U., Hans, J., Geißler, T., Meier, L., Keppler, F. \& Krammer, G. Vanilla authenticity control by DNA barcoding and isotope data aggregation. Flavour Frag. J. 32, 228-237. 
https://doi.org/10.1002/ffj.3379 (2017).

23. Lee, H. J., Feng, X. J., Mastalerz, M. \& Feakins, S. J. Characterizing lignin: combining lignin phenol, methoxy quantification, and dual stable carbon and hydrogen isotopic techniques. Org. Geochem. 136, 103894. https://doi.org/10.1016/j.orggeochem.2019.07.003 (2019).

24. Keppler, F., Kalin, R. M., Harper, D. B., McRoberts, W. C. \& Hamilton, J. T. G. Carbon isotope anomaly in the major plant $\mathrm{C}_{1}$ pool and its global biogeochemical implications. Biogeosciences 1, 123-131. https://doi.org/10.5194/bgd-1-393-2004 (2004).

25. Keppler, F., Harper, D. B., Kalin, R. M., Meier-Augenstein, W., Farmer, N., Davis, S., Schmidt, H. L., Brown, D. M. \& Hamilton, J. T. G. Stable hydrogen isotope ratios of lignin methoxyl groups as a paleoclimate proxy and constraint of the geographical origin of wood. New Phytol. 176, 600-609. https://doi.org/10.1111/j.1469-8137.2007.02213.x (2007).

26. Feakins, S. J., Ellsworth, P. V. \& Sternberg, L. D. S. L. Lignin methoxyl hydrogen isotope ratios in a coastal ecosystem. Geochim. Cosmochim. Ac. 121, 54-66. https://doi.org/10.1016/j.gca.2013.07.012 (2013).

27. Anhäuser, T., Hook, B, Halfar, J., Greule, M. \& Keppler, F. Earliest Eocene cold period and polar amplification-insights from $\delta^{2} \mathrm{H}$ values of lignin methoxyl groups of mummified wood. Palaeogeogr. Palaeocl. 505, 326-336. https://doi.org/10.1016/j.palaeo.2018.05.049 (2018).

28. Lu, Q. Q., Liu, X. H., Anhäuser, T., Keppler, F., Wang, Y. B., Zeng, X. M., Zhang, Q. L., Zhang, L. N., Wang, K. Y. \& Zhang, Y. Tree-ring lignin proxies in Larix gmelinii forest growing in a permafrost area of northeastern China: temporal variation and potential for climate reconstructions. Ecol. Indic. 118, 106750. https://doi.org/10.1016/j.ecolind.2020.106750 (2020).

29. Anhäuser, T., Greule, M., Zech, M., Kalbitz, K., McRoberts, C. \& Keppler, F. Stable hydrogen and carbon isotope ratios of methoxyl groups during plant litter degradation. Isot. Environ. Healt. S. 51, 143-154. https://doi.org/10.1080/10256016.2015.1013540 (2015).

30. Chauhan, P. S. Role of various bacterial enzymes in complete depolymerization of lignin: a review. Biocata. Agr. Biotech. 23, 101498. https://doi.org/10.1016/j.bcab.2020.101498 (2020).

31. Yoon, C. S. \& Ji, D. S. Effects of in vitro degradation on the weight loss and tensile properties of PLA/LPCL/HPCL blend fibers. Fiber. Polym. 6, 13-18. https://doi.org/10.1007/BF02875568 (2005).

32. Harman-Ware, A. E., Foster, C., Happs, R. M., Doeppke, C., Meunier, K., Gehan, J., Yue, F. X., Lu, F. C. \& Davis, M. Quantitative analysis of lignin monomers by a thioacidolysis method tailored for higherthroughput analysis. J. Biotechnol. 11, 1268-1273. https://doi.org/10.1002/biot.201600266 (2016).

33. Lapierre, C., Monties, B. \& Rolando, C. Thioacidolysis of poplar lignins: identification of monomeric syringyl products and characterization of guaiacyl-syringyl lignin fractions. Holzforschung 40, 113118. https://doi.org/10.1515/hfsg.1986.40.2.113 (1986).

34. Robinson, A. R. \& Mansfield, S. D. Rapid analysis of poplar lignin monomer composition by a streamlined thioacidolysis procedure and near-infrared reflectance-based prediction modeling. Plant J. 58, 706-714. https://doi.org/10.1111/j.1365-313X.2009.03808.x (2009). 
35. Wu, L., Rencoret, J., Lu, F. C., Karlen, S. D., Smith, B. G., Harris, P. J., del Río, J. C. \& Ralph, J. Tricinlignins: occurrence and quantitation of tricin in relation to phylogeny. Plant J. 88, 1045-1057. https://doi.org/10.1111/tpj.13315 (2016).

36. Greule, M., Rossmann, A., Hamilton, J. T. G. \& Keppler, F. A rapid and precise method for determination of D/H ratios of plant methoxyl groups. Rapid Commun. Mass Sp. 22, 3983-3988. https://doi.org/10.1002/rcm.3817 (2008).

37. Greule, M., Wieland, A. \& Keppler, F. Measurements and applications of $\delta^{2} H$ values of wood lignin methoxy groups for paleoclimatic studies. Quaternary Sci. Rev. 268, 107107. https://doi.org/10.1016/j.quascirev.2021.107107 (2021).

38. Greule, M., Moossen, H., Lloyd, M. K., Geilmann, H., Brand, W. A., Eiler, J. M., Qi, H. P. \& Keppler, F. Three wood isotopic reference materials for $\delta^{2} \mathrm{H}$ and $\delta^{13} \mathrm{C}$ measurements of plant methoxy groups. Chem. Geol. 533, 119428. https://doi.org/10.1016/j.chemgeo.2019.119428 (2020).

39. Brand, W. A. \& Coplen, T. B. Stable isotope deltas: tiny, yet robust signatures in nature. Isot. Environ. Healt. S. 48, 393-409. https://doi.org/10.1080/10256016.2012.666977 (2012).

40. Cui, T. W., Yuan, B., Guo, H. W., Tian, H., Wang, W. M., Ma, Y. Q., Li, C. Z. \& Fei, Q. Enhanced lignin biodegradation by consortium of white rot fungi: microbial synergistic effects and product mapping. Biotechnol. Biofuels. 14, 162. https://doi.org/10.1186/s13068-021-02011-y (2021).

41. Vipotnik, Z., Michelin, M. \& Tavares, T. Ligninolytic enzymes production during polycyclic aromatic hydrocarbons degradation: effect of soil pH, soil amendments and fungal co-cultivation. Biodegradation 32, 193-215. https://doi.org/10.1007/s10532-021-09933-2 (2021).

42. Guo, X. X., Liu, H. T. \& Wu, S. B. Humic substances developed during organic waste composting: formation mechanisms, structural properties, and agronomic functions. Sci. Total Environ. 662, 501510. https://doi.org/10.1016/j.scitotenv.2019.01.137 (2019).

43. Marmann, A., Aly, A., Lin, W. H., Wang, B.G. \& Proksch, P. Co-cultivation - a powerful emerging tool for enhancing the chemical diversity of microorganisms. Marine Drugs 12, 1043-1065. https://doi.org/10.3390/md12021043 (2014).

44. Kundariya, N., Mohanty, S. S., Varjani, S., Ngo, H. H., Wong, J. W. C., Taherzadeh, M. J., Chang, J. S., Ng, H. Y., Kim, S. H. \& Bui, X. T. A review on integrated approaches for municipal solid waste for environmental and economical relevance: monitoring tools, technologies, and strategic innovations. Bioresource Technol. 342, 125982. https://doi.org/10.1016/j.biortech.2021.125982 (2021).

45. Ashokkumar, V., Venkatkarthick, R., Jayashree, S., Chuetor, S., Dharmaraj, S., Kumar, G., Chen, W. H. \& Ngamcharussrivichai, C. Recent advances in lignocellulosic biomass for biofuels and value-added bioproducts-a critical review. Bioresource Technol. 345, 126195. https://doi.org/10.1016/j.biortech.2021.126195 (2022).

46. Bugg, T. D., Ahmad, M., Hardiman, E. M. \& Singh, R. The emerging role for bacteria in lignin degradation and bio-product formation. Curr. Opin. Biotech. 22, 394-400. https://doi.org/10.1016/j.copbio.2010.10.009 (2011). 
47. Meehnian, H., Jana, A. K. \& Jana, M. M. Pretreatment of cotton stalks by synergistic interaction of Daedalea flavida and Phlebia radiata in co-culture for improvement in delignification and saccharification. Int. Biodeter. Biodegr. 117, 68-77. https://doi.org/10.1016/j.ibiod.2016.11.022 (2017).

48. Andlar, M., Rezic, T., Mardetko, N., Kracher, D., Ludwig, R. \& Santek, B. Lignocellulose degradation: an overview of fungi and fungal enzymes involved in lignocellulose degradation. Eng. Life Sci. 18, 768778. https://doi.org/10.1002/elsc.201800039 (2018).

49. Kumar, M., You, S., Beiyuan, J., Luo, G., Gupta, J., Kumar, S., Singh, L., Zhang, S. \& Tsang, D. C. W. Lignin valorization by bacterial genus Pseudomonas: state-of-the-art review and prospects. Bioresource Technol. 320, 124412. https://doi.org/10.1016/j.biortech.2020.124412 (2021).

50. Chi, Y., Hatakka, A. \& Maijala, P. Can co-culturing of two white-rot fungi increase lignin degradation and the production of lignin-degrading enzymes? Int. Biodeter. Biodegr. 59, 32-39. https://doi.org/10.1016/j.ibiod.2006.06.025 (2007).

51. Zhang, S. T., Xiao, J. L., Wang, G. \& Chen, G. Enzymatic hydrolysis of lignin by ligninolytic enzymes and analysis of the hydrolyzed lignin products. Bioresource Technol. 304, 122975. https://doi.org/10.1016/j.biortech.2020.122975 (2021).

52. Graf, N. Genetic engineering of Pseudomonas putida KT2440 for rapid and high-yield production of vanillin from ferulic acid. Appl. Microbiol. Biot. 98, 137-149. https://doi.org/10.1007/s00253-0135303-1 (2014).

53. Venkatesagowda, B. \& Dekker, R. F. H. Microbial demethylation of lignin: evidence of enzymes participating in the removal of methyl/methoxyl groups. Enzyme. Microb. Tech. 147, 109780. https://doi.org/10.1016/j.enzmictec.2021.109780 (2021).

54. Peng, Y., Nicastro, K. H., Epps, T. H. \& Wu, C. Methoxy groups reduced the estrogenic activity of ligninderivable replacements relative to bisphenol $\mathrm{A}$ and bisphenol $\mathrm{F}$ as studied through two in vitro assays. Food Chem. 338, 127656. https://doi.org/10.1016/j.foodchem.2020.127656 (2021).

55. Das, S., Majumdar, B. \& Saha, A. R. Biodegradation of plant pectin and hemicelluloses with three novel Bacillus pumilus strains and their combined application for quality jute fibre production. Agr. Res. 4, 354-364. https://doi.org/10.1007/s40003-015-0188-0 (2015).

56. Fischer, A., Gehre, M., Breitfeld, J., Richnow, H. H. \& Vogt, C. Carbon and hydrogen isotope fractionation of benzene during biodegradation under sulfate-reducing conditions: a laboratory to field site approach. Rapid Commun. Mass Sp. 23, 2439-2447. https://doi.org/10.1002/rcm.4049 (2009).

57. Cui, M. C., Zhang, W. B., Fang, J., Liang, Q. Q. \& Liu, D. X. Carbon and hydrogen isotope fractionation during anaerobic biodegradation of quinoline and 3-methylquinolin. Appl. Microbiol. Biot. 101, 65636572. https://doi.org/10.1007/s00253-017-8379-1 (2017).

\section{Figures}




\section{Figure 1}

The changes in degradation weight loss $(D W L)$ and net degradation loss ( $N D L$, difference in $D W L$ value between the inoculation experiment and the uninoculation control) of garden biomass during the 15-day experiments at 2-day intervals. Italics lines and equations represent the strength of the linear fit of the $N D L$ over the 15-day experiments. Experiments: Con., uninoculated control; PM, Pseudomonas mandelii; $\mathrm{AF}$, Aspergillus fumigatus; $\mathrm{PM}+\mathrm{AF}, \mathrm{co}-\mathrm{culture}$ of the two microbes. Different letters represent a significant difference $(P<0.05)$ at different experiments.

\section{Figure 2}

Temporal variations in the content of (a) guaiacyl monolignol (G-lignin), (b) syringyl monolignol (S-lignin), and (c) the sum of monolignol for these two forms (G\&S-lignin) in the degradation residues during the 15day experiments at 2-day intervals. Experiments: Con., uninoculated control; PM, Pseudomonas mandelii, $\mathrm{AF}$, Aspergillus fumigatus; $\mathrm{PM}+\mathrm{AF}$, co-culture of the two microbes. Different letters represent a significant difference $(P<0.05)$ at different experiments.

\section{Figure 3}

Net loss of G- and S-lignin monomers in the three inoculated experiments, (a) net degradation loss (NDL, difference in lignin monomer contents between the inoculation experiments and the uninoculation control) and (b) net degradation loss rate (NDR, net degradation loss of lignin monomer contents at every degradation stage). Italics lines and equations represent the strength of the linear fit of the NDL over the 15-day experiments. In the boxplots, white squares represent mean values, the horizontal lines represent median values, the boxes represent the $25^{\text {th }}$ to the $75^{\text {th }}$ percentiles, and whiskers represent the $95 \%$ confidence interval. Experiments: PM, Pseudomonas mandelii, AF, Aspergillus fumigatus, PM+AF, coculture of the two microbes. Different letters represent a significant difference $(P<0.05)$ at different experiments. 


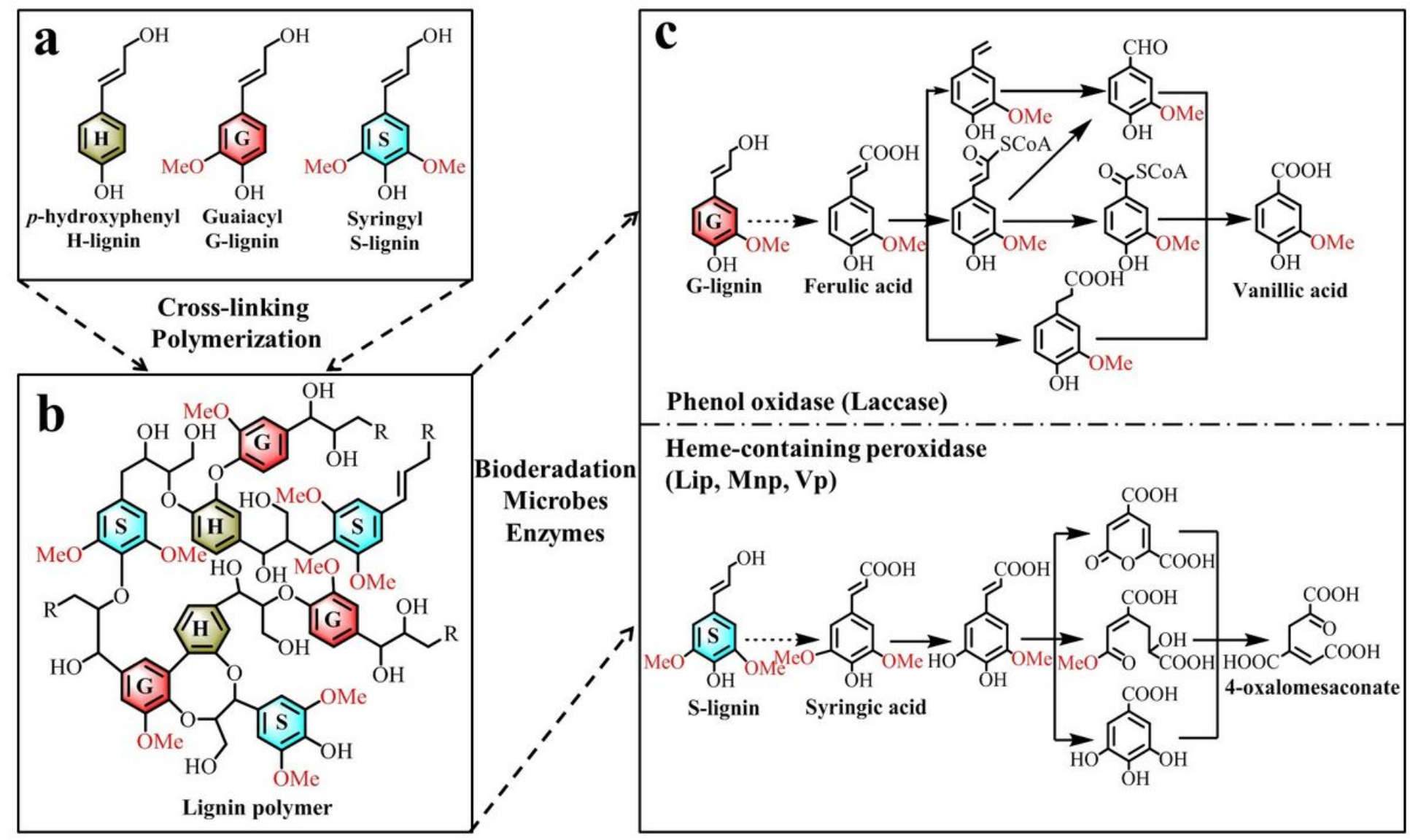

Figure 4

The chemical compositions (a), polymeric structures (b), and biodegradation pathways (c) for ligninbased aromatic compounds ${ }^{15}$. Lip, lignin peroxidase; Mnp, manganese peroxidase; Vp, versatile peroxidase.

\section{Figure 5}

Temporal variations in (a) lignin monomers ratio (G-lignin / S-lignin, $G / S$ ) and (b) stable hydrogen isotope values $\left(\delta^{2} \mathrm{H}_{\mathrm{LM}}\right)$ of lignin methoxy groups in the degradation residues. Italics lines and equations represent the strength of the linear fit of the $\mathrm{G} / \mathrm{S}$ ratio over the 15-day experiments. In the boxplots, white squares represent mean values, the horizontal lines represent median values, the boxes represent the $25^{\text {th }}$ to the $75^{\text {th }}$ percentiles, whiskers represent the $95 \%$ confidence interval, and green diamond represent outliers. Different letters represent a significant difference $(P<0.05)$ at different experiments. Ini., initial $\delta^{2} \mathrm{H}_{\mathrm{LM}}$ 
value of bulk material; Con., uninoculated control; PM, Pseudomonas mandelii; AF, Aspergillus fumigatus; $\mathrm{PM}+\mathrm{AF}(\mathrm{P}+\mathrm{A})$, co-culture of the two microbes.

\section{Supplementary Files}

This is a list of supplementary files associated with this preprint. Click to download.

- Supplementaryinformation.pdf 